Indonesian Journal of EFL and Linguistics

Vol. 6 No. 1, 2021

eISSN: 2503-4197, pISSN: 2527-5070

www. indonesian-efl-journal.org

doi: http://dx.doi.org/10.21462/ijefl.v6i1.349

\title{
Lexical Richness in Scientific Journal Articles: A Comparison between ESL and EFL Writers
}

\author{
Sumit Choemue \\ Xavier Learning Community, Chiang Rai, Thailand, \\ Sanata Dharma University, Indonesia \\ sumit.1996art@gmail.com \\ Barli Bram \\ Sanata Dharma University, Yogyakarta, Indonesia \\ Corresponding author: barli@usd.ac.id
}

\begin{abstract}
:
This study investigated lexical richness in research articles published by writers of ESL and EFL in the ASEAN countries. The question was whether there were any significant similarities and differences in terms of lexical richness in research articles between these two groups. The researchers employed three different lexical measures to find out the answer: (a) lexical density (how many content words were used), (b) lexical diversity (how wide-ranging words were used), and (c) lexical sophistication (how many advanced and unusual words were used). The primary data consisted of 40 research articles published by two ESL countries, namely Malaysia and the Philippines, and the other two EFL countries: Indonesia and Thailand and were taken from the Directory of Open Access Journals (DOAJ) and Bielefeld Academic Search Engine (BASE). The researchers analyzed the data by utilizing three measurement tools namely CLAWS Tagger, Moving-Average-TypeToken-Ratio (MATTR), and VocabProfiler, and compared the results between ESL and EFL using the Mann-Whitney $U$ test. Interestingly, despite different total tokens in several aspects, the data analysis results indicated no significant difference between ESL and EFL writers in terms of lexical richness and how they employed vocabulary in their research articles. This study further discussed factors
\end{abstract}


Sumit Choemue \& Barli Bram

influencing the use of vocabulary by two groups and concluded with limitations of the study and future research directions.

Keywords: lexical richness, vocabulary knowledge, scientific journal articles, academic writing

\section{INTRODUCTION}

The significant contribution of vocabulary (lexical) knowledge to non-native English speakers' (NNSs) writing quality (also to the natives, see Engber, 1995) has drawn a great deal of interest among scholars in the past decades, for example, Laufer and Nation (1995), Schmitt (2000), Hoover (2003), Johansson (2009), Sišková (2012), Bestgen (2017), and Ha (2019). Schmitt (2000) defines vocabulary knowledge as a robust foundation for English learners in performing four basic language skills effectively. In other words, the learners' vocabulary knowledge generally indicates how well they can listen, communicate, read, and write spontaneously (Azodi, Karimi, \& Vaezi, 2014). In the literature, scholars consider vocabulary knowledge as a key indicator to effective and successful academic writings since it can be used to determine the quality of texts (González-López \& López-López, 2015). That is because employing a variety of words in writing tasks to avoid "monotonous and tedious tone" demonstrates that somehow the writers have a rich lexical background and familiarity with diverse English texts (Djiwandono, 2016). Also, "a well-used rich vocabulary is likely to have a positive effect on the readers" (Laufer \& Nation, 1995, p. 308).

As vocabulary is an essential component of sentences, paragraphs, and entire texts, Laufer and Nation (1995) postulate that the quality of the texts can be estimated by measuring lexical richness. Hoover (2003) defines lexical richness as the ratio of types of words to the total words (token) written in a text. According to Djiwandono (2016), the term type denotes the different types of words in the text, while token refers to the total quantity of words used. For example, the last sentence contains 23 "different words" (tokens). However, some words (the, of, words) are repeated more than once. Hence, there are 14 "unique words" (types), and the type-token ratio (TTR) of this sentence is $14 / 23$ or 0.60 . In this respect, measures of lexical richness have their primary purpose to quantify the degree to which a writer is using various and extensive vocabulary (Laufer \& Nation, 1995, p. 307).

Regarding the investigation of lexical richness, a number of empirical studies have been successful in measuring lexical richness and its occurrences in different types of writings of English learners, such as expository, argumentative, theses, and 
reports (Astridya, 2020). To date, nevertheless, investigations into the variety of lexical items in research articles written by ESL and EFL writers have not been substantial. Besides, although the investigation of lexical knowledge has gained popularity in several countries, there is still a limited amount of such kind of research carried out in ASEAN. For example, Indarti (2020) conducted his study in Indonesia to investigate lexical richness in "newspaper editorials" written by ESL and EFL writers of ASEAN. Similarly, he selected four countries, namely Malaysia, Philippines, Thailand, and Indonesia, to measure similarities and differences of lexical richness across the countries. To measure, he employed the Type Token Ratio (TTR) and Lexical Frequency Profile (LFP) created by Laufer and Nation (1995). The results presented that ESL writers produced more varied words than EFL did, and it also implied that English was more broadly used in education and governance policy in ESL countries. Furthermore, Ibrahim, Muhamad, and Esa (2019) investigated 139 essays of EFL university students and 140 essays of thirdyear university students in Malaysia to find out the 1,000 and 2,000 words, AWL, and the use of the Off-word lists between these two groups. This study utilized the RANGE program to analyze the data. The significant finding of this study was that the results from the analysis could be used for the automatic feedback for the learners to avoid "repetitive use of some levels of vocabulary" (p. 180) in producing quality academic writings. Meanwhile, Djiwandono (2016) carried out an empirical study exploring lexical richness in 18 academic papers but compared between senior students and their lecturers. Through the type-token ratio (TTR), the findings indicated that the TTR and academic words were higher in lecturers' essays. On the other hand, students' essays produced more 2000-word levels and off-list words.

In short, we could see from studies discussed above that there were scarce investigations of lexical richness in academic papers (scientific journal articles) in Southeast Asia countries. Moreover, to the best knowledge of the researchers, there has been no study that investigates to compare lexical richness and how vocabulary is employed in research articles by ESL and EFL writers in this region. Accordingly, to bridge this gap, this study was carried out aiming at investigating the lexical richness of scientific journal articles published by ESL and EFL countries to find out the similarities and differences and take further actions to develop their scientific journal articles. For this investigation, the researchers measured three different categories of lexical richness (Read, 2000). To begin with, the lexical density was first measured. Johansson (2009) asserts that lexical density is most often referred to as a measure of the number of content words i.e. nouns, verbs, adjectives, and adverbs, to the overall number of words in the text. Through this measure, the researchers were able to identify that a text using a high proportion of content words than function words contained more information (Johansson, 2009, 66). Secondly, lexical diversity or lexical variation is a measure of how wide-ranging vocabulary is used in the text (how many various words are used) (Juanggo, 2018). To be more specific, the more a writer uses different words in a text, with a small number of 


\section{Sumit Choemue \& Barli Bram}

repetitions, the higher the lexical diversity. This notion has long been affirmed by Laufer and Nation (1995) when they reported in their study that good writings depicted more diverse vocabulary. Thirdly, lexical sophistication is a measure intended to find out how many "unusual" or advanced words are employed by the writers in their writings. Indarti (2019) reported that English vocabulary could be classified into two main categories, namely high-frequency words and lowfrequency words. The high-frequency words are divided into a 1000-word level and 2000-word level and frequently appear in all kinds of text. On the other hand, the low-frequency words such as in Academic Word List (AWL) and Off-list words are infrequently employed by the writers across texts. Yet, the low-frequency words are believed to be a reliable pointer of the richness of writings, especially in academic ones (Laufer \& Nation, 1995). To this end, the researchers formulated one research question to navigate this study as follows:

Is there any significant similarity and difference in terms of lexical richness in the forty scientific journal articles published by the writers of ESL and EFL among four countries in the ASEAN?

Based on this research question, the researchers formulated the following three null hypotheses and three alternative hypotheses:

H1: There is no difference between ESL writers' and EFL writers' scientific journal articles in terms of lexical density.

- H1.1 Scientific journal articles by ESL writers have higher lexical density than those written by EFL writers.

H2: There is no difference between ESL writers' and EFL writers' scientific journal articles in terms of lexical diversity.

- H2.1 Scientific journal articles by ESL writers have higher lexical diversity than those written by EFL writers.

H3: There is no difference between ESL writers' and EFL writers' scientific journal articles in terms of lexical sophistication.

- H3.1 Scientific journal articles by ESL writers have higher lexical sophistication than those written by EFL writers.

\section{LITERATURE REVIEW}

\subsection{Vocabulary Knowledge and Academic Writing}

The term "vocabulary knowledge" or "lexical knowledge" has been regarded as a significant indicator of the quality of both native and non-native academic writing (Laufer \& Nation, 1995; Šišková, 2012). When exploring deeper, we all realize that when a learner begins to learn the English language, he or she is likely to first start with learning vocabulary since it provides a fundamental basis to comprehend all 
skills needed in the language (Failasofah, 2018). To be more detailed, Juanggo (2018) emphasizes that, with sufficient vocabulary knowledge, a learner would be able to fully understand and later express or convey their ideas and thoughts correctly and appropriately. On the other hand, with inadequate vocabulary knowledge and the ability to obtain new words, the learner would inevitably face challenges and communicative difficulties (Azodi et al., 2014).

Given that vocabulary acquisition is a complex process, Ha (2019) emphasizes the significant role of English teachers in scaffolding learners in acquiring new vocabulary items in the early phases of language learning. Moreover, this fundamental stage will influence how effective they are in performing academic writing when entering a higher stage. Additionally, for the most worthwhile vocabulary list, Nation and Meara (as cited in Ha, 2019) state that "Michael West's (1953) General Service List (GSL) of English words is among the most useful lists for L2 learners to use." These high-frequency words could be classified into a 1000word level and a 2000-word level (Indarti, 2019). Besides, it is worth noting that English learners who can recognize less than 1,000-word families are likely to struggle in understanding a normal text (Azodi et al., 2014).

In addition to the general word list discussed above, Coxhead (2000) collected and postulates 570 Academic Word List (AWL) by analyzing more than 400 academic texts. This list "constitutes a specialized vocabulary with coverage of academic texts, regardless of the subject area" (Ha, 2019, p. 6). Some examples of AWL are: acknowledge, commence, demonstrate, enforce, fluctuate, incorporate, mutual, phenomenon, reinforce, subsidy, undergo, and welfare. Generally, the AWL is embedded in the low-frequency words that are uncommonly employed by the writers across the texts. Nonetheless, as asserted by Laufer and Nation (1995), these low-frequency words are extensively acknowledged to be a dependable indicator of the richness of writings, especially in academic papers. Likewise, Arnaud and Linnarud (cited in Ha, 2019) bring out that English learners who can use "rare words" in writing tasks tend to carry a high level of language proficiency.

\subsection{Measuring Lexical Richness}

In general, measuring lexical richness, which involves applied linguistics and the framework of word frequency contributions (Failasofah, 2018), is concerned with how many distinctive words are used in a text. Additionally, it is worth mentioning that "there is no one measure of lexical richness which would give perfect results, researchers tend to use several different measures to obtain more information" (Šišková, 2012, p. 31). In this respect and built on Read's (2000) study, measuring lexical richness in this current study can be accomplished in three different measures, namely lexical density, lexical diversity, and lexical sophistication. 


\subsubsection{Lexical density}

According to To, Fan, and Thomas (2013), the definition of "density" refers to the development of words or the level of wording in written and spoken texts that creates "a kind of complexity" (p. 64). In a nutshell, lexical density is used in the term of the measurement of the proportion of content words such as nouns, verbs, adjectives, and adverbs to the overall number of tokens (Johansson, 2009). In other words, a text using more content words than function words (prepositions, interjections, pronouns, and conjunctions) indicates more information or what Johansson calls an "information packaging" (p. 65).

To date, different measurements of lexical density have been utilized. Lei and Yang (2020) state that, originally, the term lexical density is coined and proposed by Ure (1971) as "the ratio of lexical words (opposed to grammatical words) to the total number of words in a text" (p. 5). Later, this formula has been developed and refined by several scholars. One important study is from Laufer and Nation (1995). By examining vocabulary size and use of L2 learners' writing productions, they propose the following formula of lexical density measurement.

$$
\text { Lexical density }=\frac{\text { Number of lexical tokens } x 100}{\text { Total number of tokens }}
$$

In the simplest definition of lexical density, Laufer and Nation (1995) define it as a percentage of lexical words in the text. Similarly, in this present study, the researchers simply used the ratio of the lexical words or content words against the total number of tokens to determine its percentage. The following sentence demonstrates how lexical density is measured in this study. For example, the way people consume newspapers and their reading behaviors have been changed. This sentence presents seven lexical items and five grammatical items. Thus, the lexical density of this sentence would be fifty-eight percent or 0.58. Additionally, following the study by Sari (2019), the researchers employed the software CLAWS Tagger (Constituent Likelihood Automatic Word-tagging System) to measure lexical density in this study. CLAWS was claimed to perform 96-97\% accuracy with simplicity and availability for all at http://ucrel.lancs.ac.uk/claws/. Besides, Sari (2019) employed this tool and pointed out its effectiveness and practicality.

\subsubsection{Lexical diversity}

Johansson (2009) asserts that lexical diversity measures how many different words are used in a text (see also Indarti, 2019; Juanggo, 2018; cf Fauzan, Lubis, \& Kurniawan, 2020; Rochma, \& Triyono, 2019). Therefore, the more a writer uses varied vocabulary when writing a composition, the higher the lexical diversity the composition possesses (Juanggo, 2018). Concerning its measure, the Type-Token Ratio (TTR) is considered to be the best known quantitative measurement of lexical 
diversity as it gains popularity among researchers (Astridya, 2020). Laufer and Nation (1995, p. 310) framed the following formula for measuring lexical diversity.

$$
\text { Lexical diversity }=\frac{\text { Number of types } x 100}{\text { Number of tokens }}
$$

However, TTR measure holds one controversial problem since it has been widely recognized to be an unsatisfactory measure of lexical diversity (Covington \& McFall, 2010). Laufer and Nation (1995) mention that the TTR has been criticized for its instability since it is unstable for short texts and the text length influences the reliable results to determine the lexical diversity. Concerning its weakness, many researchers develop and propose different alternative approaches to resolve its great sensitivity to text length. For the simplest solution, Laufer and Nation (1995) suggest that the researchers select compositions with equal lengths to avoid the problem. Previously, Covington and McFall (2010) proposed a new approach, namely Moving-Average-Type-Token-Ratio (MATTR) to measure lexical diversity. MATTR is designed to facilitate researchers in calculating the average mean of TTR with various samples regardless of different lengths. Accordingly, this study also utilized MATTR to measure lexical diversity since some other studies have been carried out and demonstrated the validity of MATTR. This measure is reliable and not influenced by the length of texts because it is "considered as a lengthindependent measure" (Lei \& Yang, 2020, p. 5).

\subsubsection{Lexical Sophistication}

Commonly, lexical sophistication (or "rareness" in Read, 2000) measures learners' written production based on the proportion of "advanced words" employed by the learners in their writings (Bestgen, 2017; Juanggo, 2018; Laufer \& Nation, 1995). Furthermore, the following formula is proposed by Laufer and Nation (1995) and widely used in order to calculate advanced vocabulary in a text in the form of a percentage.

$$
\text { Lexical sophistication }=\frac{\text { Number of advanced tokens } x 100}{\text { Total number of lexical tokens }}
$$

According to Lei and Yang (2020), Lexical Frequency Profile (LFP) is considered the most commonly used method in measuring lexical sophistication. Laufer and Nation (1995) describe that "LFP shows the percentage of words a learner uses a different vocabulary frequency levels in his or her writing - or, put differently, the relative proportion of words from different frequency levels" (p. 311). Table 2.1 illustrates the terminology of LFP used in Indarti (2020). 
Sumit Choemue \& Barli Bram

Table: 1 Different terms of LFP (Indarti, 2020)

\begin{tabular}{lll}
\hline Frequency level & Symbol & \\
\hline The first 1000 words (1-1000) & K1 words & \\
The second 1000 words (1001-2000) & K2 words & \\
Academic Word Lists & AWL & \\
Off-List words & - & $\mathrm{N}$ \\
Number of words & Tokens & $\mathrm{V}$ \\
Number of different words & Types & $\mathrm{V} 1$ \\
Number of words occurring once & $\mathrm{V} 1$ & $\mathrm{~V} / \mathrm{N}$ \\
Type/token ratio & TTR & \\
\hline
\end{tabular}

Table 1 describes that LFP produces a profile containing lexical content of the text in various frequency bands (Azodi et al., 2014). These bands are further categorized into three words list: (a) the first one thousand most frequent words of English (K1), (b) the second one thousand most frequent words (K2) (which are based on the General Service List (GSL) proposed by West (1953), and (c) the 570 most frequent academic words (AWL) (Coxhead, 2000). Furthermore, the off-list words present vocabulary that does not appear in any of the mentioned categories. In addition, LFP is found to be "simple to run, effective output, and able to produce information instantly" (Ibrahim, Muhamad, \& Esa, 2019, p. 176). In this current study, the researchers employed the VocabProfilers to analyze lexical sophistication. This program is developed by Tom Cobb, and it is made available on his website (https://www.lextutor.ca/vp/).

\subsection{English in Southeast Asia (The Circle Model of World Englishes)}

As we know, English is perceived as an international language and used by people from wide-ranging cultures. As reported by Deerajviset (2015), Asians have become the biggest number of English speakers who use English as a second and foreign language. Especially, English has played a major role in the Association of Southeast Asian Nations (ASEAN) in recent years. However, it is worth noting that English varieties in ASEAN are somewhat varied and can be primarily categorized into two groups (Low \& Hashim, 2012). Regarding Kachru's (1985) "three-circle model," the first group are in the outer circle, including countries that were formerly colonized by British and American. The status of English in these countries is officially used as a second language (L2) e.g. Malaysia, Singapore, Philippines, and Brunei Darussalam. The second group, which includes the expanding circle, refers to any countries where English is taught in schools as a foreign language (EFL) and it is not officially used in everyday life, such as Indonesia, Vietnam, Laos, and Thailand. This current study only selected four countries, namely the Philippines, Malaysia, Indonesia, and Thailand, to represent ESL and EFL countries. The following sections will briefly elaborate on English status in each country. 
To begin with, the Philippines was colonized by the United States. Therefore, English has played a special status in this country. Previously, the Philippine language policy was Bilingual Education Policy (BEP) which mandates that Filipino be the national language and English the official language (Martin, 2014). In contrast, this BEP was widely criticized concerning its impact on Filipino children's learning outcomes. Thus, Mother-Tongue Based Multilingual Education was introduced in 2009 regarding the importance of using the students' mother tongue as the medium of instruction. As a significant report, studies demonstrated that learning in the mother tongue essentially increased students' learning outcomes (Martin, 2014). Next, Malaysia was a former colony of Britain. The English language has been highly regarded as a significant role of the country, as witnessed through the government's effort to maintain the standard of the language. On the other hand, Dumanig and Symaco (2012) pointed out that Malaysia also encountered a "rising call of nationalism and the need to preserve cultural identity" (p. 105). Accordingly, the Malaysian government agreed to increase the role of Malay as a medium of instruction in 2012.

Thirdly, scholars have continually carried out studies to examine the current situation of English in Indonesia and revealed that English status has been turned into an international language due to the former Dutch colony. Furthermore, Deerajviset (2015) asserted that the ASEAN establishment caused English to broaden across the country promptly. On the other hand, studies found that the country still demanded competent and linguistically proficient English teachers. Hence, increasing English teachers' professional development was found to be essential. In the case of Thailand, English is taught as a compulsory subject from primary school to higher education. However, recent researchers have found several aspects influencing ineffective language acquisition. For instance, teachers merely assist students in passing the national examination (Noom-Ura, 2013). To reform language instruction and strengthen bilingual programs, the ministry of education has promoted the "English Program" or EP to support students' language exposure (Ulla, 2018). Also, some native and non-native-speaking teachers have been employed to enhance students' English proficiency.

\section{RESEARCH METHODOLOGY}

\subsection{Research Approach}

The primary objective of this study was to examine lexical richness in scientific journal articles written by ESL and EFL authors and were published in the ASEAN countries. To accomplish this aim, a quantitative study was carried out. Apuke (2017) points out that "a quantitative research method deals with quantifying and analysis variables to get results. It involves the utilization and analysis of numerical data using specific statistical techniques" (p. 41). Accordingly, a quantitative approach enables the researchers to describe, analyze, and figure out the similarities and differences of vocabulary used in the journal articles in this study. Furthermore, 
the content analysis which "defines the existence of certain words, themes, or concepts within some given texts" was used to investigate lexical richness in collected research articles. In addition, by utilizing online lexical analysis instruments, three different measures of lexical richness, namely lexical density, lexical diversity, and lexical sophistication, were analyzed.

\subsection{Corpora and Collection Procedures}

The corpora of this study consisted of 40 (forty) research articles written by nonnative speakers of English in ASEAN countries with wide-ranging levels of writing capabilities. Out of ten countries, four countries were purposefully selected to be involved in this study since they distinctively demonstrate their significant role and status of the English language in the region. First, the Philippines and Malaysia, where were colonized by native-speaking countries (American and British), exemplified the countries that used English as a second language (ESL). On the other hand, Indonesia, a multicultural and multilingual country, and Thailand were a selection of the countries where English is used as a foreign language (EFL). Furthermore, these research articles (papers) were all published in numerous accredited journals e.g. TESOL International Journal, Malaysian Journal of Learning and Instruction, Indonesian Journal Of Applied Linguistics, and LEARN Journal in the last three years (2017-2020, see table 2 for the statistics).

Table: 2 Statistics of the 40 articles written by ESL and EFL writers

\begin{tabular}{|c|c|c|c|}
\hline & Country & Article & $\begin{array}{l}\text { No. of } \\
\text { words }\end{array}$ \\
\hline \multirow[t]{2}{*}{ ESL } & Philippines & $\begin{array}{l}\text { Daguay-James \& Bulusan (2020); Vallente (2020); } \\
\text { Aquino \& De Vera (2018); Parangan \& Buslon (2020); } \\
\text { Tan, Polong, Collates \& Torres (2020); Pamintuan, } \\
\text { Mallari, Garcia, Galang \& Buduan (2018); Montejo \& } \\
\text { Jamon (2018); Talosa \& Maguddayao (2018); Banatao } \\
\text { \& Malenab-Temporal (2018); Sioco \& De Vera (2018). }\end{array}$ & 10,688 \\
\hline & Malaysia & $\begin{array}{l}\text { Fakaruddin \& Nor (2020); Di, Zailani \& Ismail (2020); } \\
\text { Krishnaswamy, Koon \& Annamalai (2019); } \\
\text { Ganapathy, Tan \& Phan (2020); Singh (2020); Adams, } \\
\text { Joo, Sumintono \& Pei (2020); Benlahcene, Awang- } \\
\text { Hashim \& Kaur (2020); Jeyaraj (2020); Ma’dan, Imail } \\
\text { \& Daud (2020); Fong \& DeWitt (2019). }\end{array}$ & 11,183 \\
\hline \multirow[t]{2}{*}{ EFL } & Indonesia & $\begin{array}{l}\text { Handayani, Drajati \& Ngadiso (2020); Pitoyo, Sumardi } \\
\text { \& Asib (2020); Nugrahani \& Bram (2020); Prasojo, } \\
\text { Wijayanti, Yuliana, Agus, Habibi \& Yaakob (2020); } \\
\text { Amin \& Sundari (2020); Damanik \& Mulyadi (2020); } \\
\text { Subekti (2020); Sutono \& Budiraharjo (2020); Siregar, } \\
\text { Fauziati \& Marmanto (2020); Kusumaningputri (2020). }\end{array}$ & 10,223 \\
\hline & Thailand & Supakorn (2020); Chanprapun (2020); Khongput & 10,453 \\
\hline
\end{tabular}




\begin{tabular}{|c|c|c|c|}
\hline & & $\begin{array}{l}\text { (2020); Wadsorn (2017); Jaiprasong \& Pongpairoj } \\
\text { (2020); Piamsai (2020); Arya (2020); Inpeng \& } \\
\text { Nomnian (2020); Kitikanan \& Sasimonton (2017); } \\
\text { Torudom \& Taylor (2017). }\end{array}$ & \\
\hline Total & 4 & 40 & 42,547 \\
\hline
\end{tabular}

For the corpora selection, the researchers follow several procedures. First, the researchers utilized two online search engines, namely the Directory of Open Access Journals (DOAJ) (https://doaj.org/) and Bielefeld Academic Search Engine (BASE) (https://www.base-search.net/) in which provide millions of open access journals and academic documents. Second, the researchers randomly downloaded 40 research articles, 10 for each chosen country, to analyze in this study. In addition, note that the major field of the articles was education. Third, the researchers compiled articles for each country and calculated the number of words (tokens) by balancing them for comparison. It is worth noting that the researchers only took chapters 1 and 5 for the analysis since they offered the writers' "original thoughts" and the other chapters usually contained numerous citations (Djiwandono, 2016). The total number of words used in this study was 42,547 tokens.

\subsection{Instruments and Data Analysis}

This study employed three different instruments or tools of lexical richness measurement. The utmost purpose of utilizing more than one tool was inspired by Šišková (2012), who pointed out that "at present, that there is no one measure of lexical richness which would give perfect results, researchers tend to use several different measures to obtain more information" (p. 31). Accordingly, Table 3 demonstrates the three measurements of the three categories of lexical richness and also their definitions applied in this study.

Table: 3 Measurements of lexical richness

\begin{tabular}{|c|c|c|}
\hline Category & Tool & Measurement \\
\hline Lexical density & CLAWS Tagger & $\begin{array}{l}\text { "The proportion of content words to } \\
\text { the total number of words used in the } \\
\text { text" }\end{array}$ \\
\hline Lexical diversity & MATTR & $\begin{array}{l}\text { "The proportion of different words to } \\
\text { the total number of words used in the } \\
\text { text" }\end{array}$ \\
\hline Lexical sophistication & VocabProfiler & $\begin{array}{l}\text { "The proportion of words used at } \\
\text { different frequency levels, in terms of } \\
\text { GSL1, GSL2, and AWL in the text" }\end{array}$ \\
\hline
\end{tabular}

Following Sari (2019), firstly, lexical density was calculated using the software CLAWS Tagger developed by University Centre for Computer Corpus Research on 
Language (UCREL), Lancaster. First, the researchers uploaded the articles to the program CLAWS. After that, the program automatically analyzed and displayed the part of speech (POS) tagging. Finally, the researchers calculated the proportion and value of content words, namely nouns, verbs, adjectives, and adverbs in tables. Secondly, the software Moving-Average-Type-Token-Ratio (MATTR) (Covington \& McFall, 2010) was operated to measure lexical diversity. The researchers decided to utilize this software due to its reliability and availability. Besides, MATTR has been utilized by previous scholars and reassured its valid and unbiased results since this software is a length-independent measure. Meanwhile, other measures such as Type-Token Ratio (TTR) are sensitive and unstable to the length of texts. Similarly, the researchers further uploaded articles one by one to the MATTR, and the program automatically calculated the types and tokens of each article. Thirdly, through Lexical Frequency Profile (LFP) proposed by Laufer and Nation (1995), the researchers applied the software named VocabProfiler (RANGE) to analyze lexical sophistication. This program calculated inserted articles and displayed: the first and second 1,000 words (K1, K2), academic word lists (AWL), and off-list words. Finally, after all, calculations were done, the researchers elaborated the results in statistic tables with percentages. Finally, to compare the statistical differences in terms of lexical density, lexical diversity, and lexical sophistication, the researchers used the Mann-Whitney $U$ test. This non-parametric test was used due to "the collected data did not conform to normality and homogeneity of variances" (Lei \& Yang, 2020, p. 10). To conclude whether or not the difference of the test is significant, the original threshold of significant difference should be $(p<.05)$. In addition, this Mann-Whitney U test was run by run by SPSS 22.0.

\section{FINDINGS}

\subsection{Lexical Density Analysis Results}

Lexical density measures the proportion of the content word (nouns, verbs, adjectives, adverbs) to the total number of tokens. To analyze the number of content words in the articles, the researchers used CLAWS Tagger. Table 4 reveals the statistic of lexical density in ESL articles.

Table: 4 Statistic of lexical density in ESL articles

\begin{tabular}{lccc}
\hline Content words & Philippines & Malaysia & Total \\
\hline Nouns & 3,209 & 3,644 & 6,853 \\
Verbs & 1,692 & 1,764 & 3,456 \\
Adjectives & 1,103 & 1,097 & 2,200 \\
Adverbs & 488 & 462 & 950 \\
Total & 6,492 & 6,967 & 13,459 \\
Tokens & 10,688 & 11,183 & 21,871 \\
\hline Lex Density & $\mathbf{0 . 6 0 7}$ & $\mathbf{0 . 6 2 2}$ & $\mathbf{0 . 6 1 5}$ \\
\hline
\end{tabular}


Table 4 shows that the total number of content words in ESL articles was 13,459, which were found in the Philippines 6,492 and 6,967 words in Malaysia. Furthermore, the table also reveals that the number of nouns (singular, plural, proper) and verbs (finite, infinitive, past, -ing, etc.) were used more in Malaysian articles than that of Filipino articles $(3,644,1,764)$. Meanwhile, the Filipino writers employed more adjectives (also comparative, superlative) and adverbs (wh-adverbs included) $(1,103,488)$. Lastly, the table depicts that the lexical density score of Malaysian articles (0.622) was higher than that of Filipino articles (0.607). Besides, the lexical density mean score of ESL country was 0.615 . Table 5 below shows the statistic of lexical density in EFL articles.

Table: 5 Statistic of Lexical Density in EFL Research Articles

\begin{tabular}{lccc}
\hline Content words & Indonesia & Thailand & Total \\
\hline Nouns & 3,139 & 3,370 & 6,509 \\
Verbs & 1,604 & 1,659 & 3,263 \\
Adjectives & 950 & 1,006 & 1,956 \\
Adverbs & 557 & 464 & 1,021 \\
Total & 6,250 & 6,499 & 12,749 \\
Tokens & 10,223 & 10,453 & 20,676 \\
\hline Lex Density & $\mathbf{0 . 6 1 1}$ & $\mathbf{0 . 6 2 1}$ & $\mathbf{0 . 6 1 6}$ \\
\hline
\end{tabular}

As shown in Table 5, 12,749 total number of content words were found in EFL articles, which used by Indonesians 6,250 and 6,499 words by Thais. The majority of content words i.e. nouns $(3,370)$, verbs $(1,659)$, and adjectives $(1,006)$ were found more in Thai articles. Hence, adverbs were the only content word used more in Indonesian articles (557). Besides, the lexical density score of Thai articles (0.621) was found to be higher than that of Indonesian articles (0.611). Nevertheless, the mean score of lexical density in EFL articles (0.616) was slightly higher. To find out the difference in terms of lexical density in ESL and EFL articles, the researchers used the Mann-Whitney $U$ test. The result was $p=1.000$ which indicated that the difference between ESL and EFL in terms of lexical density was not significant. Thus, based on this result, the null hypothesis (H1) was accepted and the alternative hypothesis (H1.1) was rejected. Accordingly, the researchers concluded that ESL and EFL writers in this study had a comparable tendency in using content words in their research articles, with slightly different numbers but was insignificant.

\subsection{Lexical Diversity Analysis Results}

To gauge ESL and EFL writers' lexical diversity in research articles, or how different words were used by measuring a total number of types divided by a total number of tokens, MATTR which is considered as an unbiased, reliable, and lengthindependent tool was used. Figure 1 presents ESL and EFL writers' lexical diversity results. 


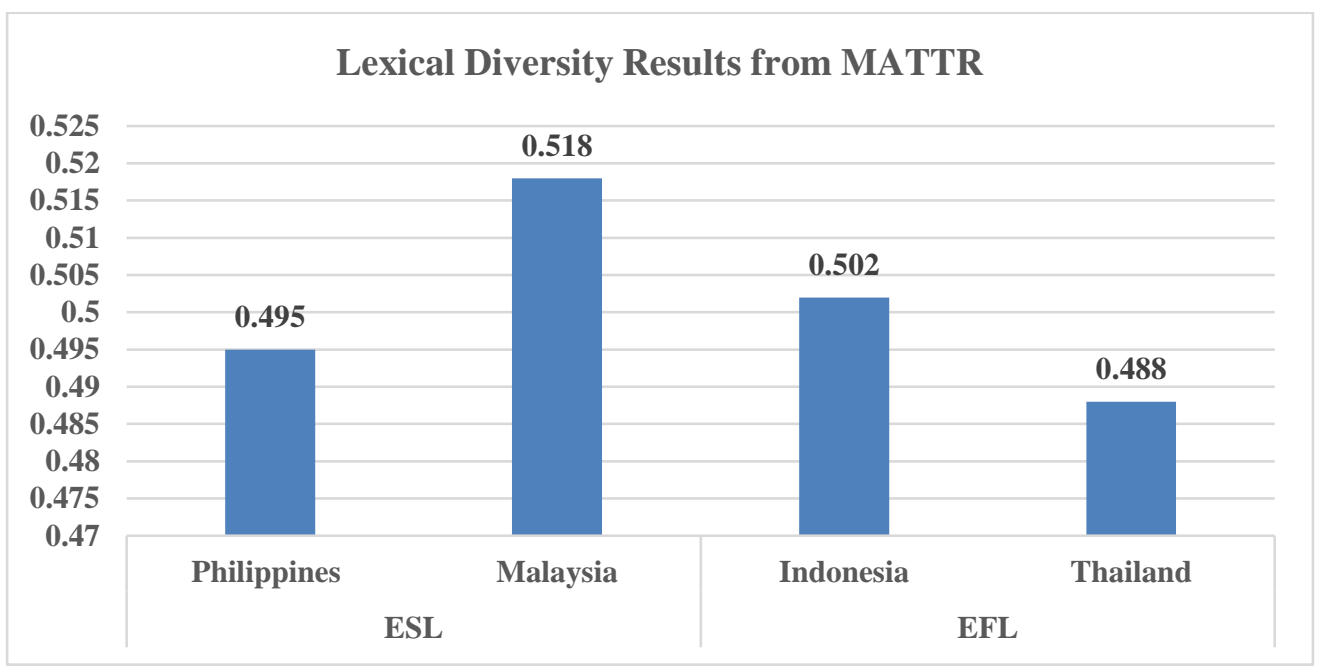

Figure: 1 ESL and EFL Writers' Lexical Diversity Results from MATTR

Regarding figure 1, it could be explained that the Malaysian articles had the highest score of lexical diversity, 0.518. Next, Indonesia was the second country (0.502), the Philippines for the third (0.495), and the lowest score of lexical diversity was Thailand with 0.488. Furthermore, in comparing these findings between ESL and EFL writers, Mann-Whitney $U$ test analysis revealed that the difference was not significant $(\mathrm{p}=.439)$. It means that the null hypothesis $(\mathrm{H} 2)$ which said there was no difference between ESL and EFL writers' scientific journal articles in terms of lexical diversity was accepted. On the other hand, the alternative hypothesis $(\mathrm{H} 2.1)$ was rejected. Therefore, similar to lexical density, the researchers concluded that there was no significant difference between ESL and EFL writers in terms of lexical diversity. In other words, the majority of the writers from both groups employed efficiently diverse varieties of vocabulary when composing scientific articles.

\subsection{Lexical Sophistication Analysis Results}

Measuring lexical sophistication or "rareness" (Read, 2000) was aimed at exploring the proportion of "advanced words" used by the writers in their writing productions. Employed VocabProfilers software, this online tool first automatically counted K-1 and K-2 word list which refers to the first and second one thousand most frequent words of English in General Service List (GSL) proposed by West (1953). These two lists do not show the sophistication of the texts. Second, the tool also calculated the number of the Academic Word List (AWL) which comprises 570 specific words frequently existing in scientific works, and the off-list words (do not include in aforementioned lists) of the term "advanced words" and levels of difficulty of the articles. In this relation, the researchers particularly considered these two lists in order to measure lexical sophistication in this study. 
Table: 6 Statistic of Lexical Sophistication in ESL Research Articles

\begin{tabular}{lcccc}
\hline Wordlist & Tokens & Types & Families & Percentage \\
\hline K-1 words & 15,474 & 1,768 & 1,007 & $70.43 \%$ \\
K-2 words & 1,127 & 395 & 266 & $5.12 \%$ \\
AWL & 2,577 & 978 & 575 & $11.72 \%$ \\
Off-list & 2,792 & 1,318 & $?$ & $12.70 \%$ \\
\hline Total & $\mathbf{2 1 , 9 7 0}$ & $\mathbf{4 , 4 5 9}$ & $\mathbf{1 , 8 4 8 + ?}$ & $\mathbf{1 0 0 \%}$ \\
\hline
\end{tabular}

Table 6 reveals that there were 2,577 (11.72\%) academic words and 2,792 (12.70\%) off-list words found in 20 research articles written by ESL authors. On the other hand, table 7 shows 2,436 (11.73\%) academic words as well as 2,801 (13.49\%) offlist words in $20 \mathrm{EFL}$ articles. These findings suggested that the proportions of AWL and off-list words employed by ESL and EFL writers were scarcely different despite a higher percentage from the EFL group.

Table: 7 Statistic of Lexical Sophistication in EFL Research Articles

\begin{tabular}{lcccc}
\hline Wordlist & Tokens & Types & Families & Percentage \\
\hline K-1 & 14,662 & 1,704 & 993 & $70.64 \%$ \\
K-2 & 855 & 361 & 242 & $4.11 \%$ \\
AWL & 2,436 & 944 & 543 & $11.73 \%$ \\
Off-list & 2,801 & 1,223 & $?$ & $13.49 \%$ \\
\hline Total & $\mathbf{2 0 , 7 5 4}$ & $\mathbf{4 , 2 3 2}$ & $\mathbf{1 , 7 7 8 + ?}$ & $\mathbf{1 0 0 \%}$ \\
\hline
\end{tabular}

Additionally, figure 2 indicates the contributions of AWL and off-list words in research articles by each country. Based on the chart, the percentages of AWL in this present study can be sequenced respectively as follows: Thailand, Malaysia, the Philippines, and Indonesia. Whereas, the contributions of off-list words found in the articles were sequential as Indonesia, Malaysia, Thailand, and the Philippines. Accordingly, the researchers concluded that Malaysian research articles possessed the highest lexical sophistication and the lowest was the Philippines'. 


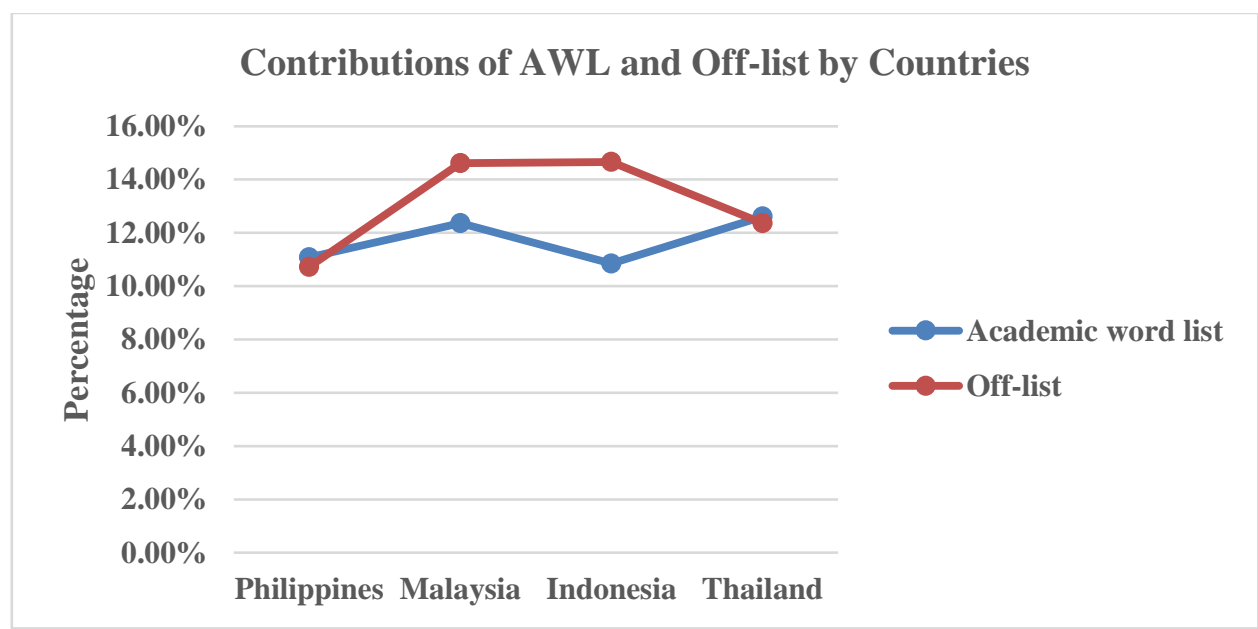

Figure: 2 Contributions of AWL and Off-List by Countries

Furthermore, consistent with lexical density and lexical diversity findings, the difference between ESL and EFL writers in terms of lexical sophistication was examined. After data analysis, Mann-Whitney $U$ test results revealed no significant difference between both groups ( $p=.439$ for AWL, $p=1.000$ for Off-list). Based on these findings, the null hypothesis (H3) was accepted and the alternative hypothesis (H3.1) was rejected. Therefore, it can be concluded that both ESL and EFL authors in this study had an equal capability of using Academic word list and Off-list in which correlated to some characteristics of scientific articles showing quality and richness of vocabulary in writing productions.

\section{DISCUSSION}

According to Laufer and Nation (1995), measures of lexical richness have the primary objective to find out the degree to which a writer uses various and extensive vocabulary (p. 307). Constructed on this definition, this study attempted to answer one research question whether or not there are significant similarities and differences in terms of lexical richness in scientific journal articles composed by ESL and EFL writers in the ASEAN region. In particular, the researchers focused on three distinct measures of lexical richness which was based on Read's (2000) study, namely lexical density, lexical diversity, and lexical sophistication.

With careful data analysis, the findings explained in the section above revealed one interesting discovery that could be used to conclude this study, that is, no significant difference regarding lexical richness between ESL and EFL writers. Although the analysis indicated varied numbers of words and percentages for each measure, the Mann-Whitney $U$ test showed the results of two-tailed value above $p=0.5$. It means that none of the null hypotheses was rejected. The results of this study were consistent with Indarti (2020), who pointed out that lexical richness in newspaper editorials by ESL and EFL was insignificant, with a slightly higher score in the ESL group. Similarly, ESL writers of this study demonstrated higher levels of English 
proficiency in using varied vocabulary than that of EFL in several aspects. In this case, Indarti (2020) explained that this finding could be clearly understood due to English was more broadly used in education and governance policy in ESL countries. As a result, these writers possessed advantages from English status and abundantly supportive environments to strengthen and cultivate their English competency more effectively.

Furthermore, the results can be discussed in light of possible factors and or reasons involving the employment of vocabulary by ESL and EFL in this study. First of all, it is worth discussing the nature and characteristics of research articles (academic papers) that influence the writers. As mentioned previously, writing high-quality research articles was challenging and demanding, especially for novice writers, since it required an appropriate linguistics competency and adequate vocabulary related to academic contexts (Engber, 1995; González-López \& López-López, 2015). Accordingly, the results could be implied that both ESL and EFL writers had a rich lexical background and similar familiarity with numerous English texts (Djiwandono, 2016) since they were capable of using varieties of words in their research articles. This is in line with (Azodi et al., 2014), who stated that the ability to use lexical knowledge throughout years of study at university increased. Also, as all selected research articles in this study were published in various accredited journals, it is inferred that the writers of ESL and EFL embraced sufficient experiences in producing "a well-used vocabulary text" (Laufer \& Nation, 1995) to publish in such high-quality journals.

The finding presenting that there was no significant difference relating to lexical richness between two groups could be a result partly of the establishment of the ASEAN Community. Deerajviset (2015) highlighted that the integration of 10 countries in this region "promotes active cooperation and mutual assistance in the education" (p. 41) and vastly accelerates the role and importance of the English language. Accordingly, each country has endeavored to promote the English language in all levels of education by implementing various approaches such as Bilingual Education Policy (BEP), English Program (EP) (Ulla, 2018), and MotherTongue Based Multilingual Education (Martin, 2014). As such, these attempts somehow affected English in this community equivalent, regardless of the colony of native-speaking countries. In consequence, the results from this study could be inferred that language proficiency of ESL and EFL countries, especially lexical knowledge, were comparable since it demonstrated insignificant difference ( $\mathrm{p}<$ $0.5)$. In short, although English is used in "a richly multicultural and multilingual" community (Kirkpatrick, 2010), English language competency regarding lexical knowledge of ESL and EFL writers in the ASEAN is on par.

Additionally, the findings from three measures of lexical richness in this study also complement other previous studies. For lexical density, Johansson (2009, p. 66) captured a text using a high amount of content words than function words contained 


\section{Sumit Choemue \& Barli Bram}

more information. From the results, the majority of ESL and EFL writers tended to use content words, with considerable scores $\mathrm{ESL}=0.615$ and $\mathrm{EFL}=0.616$. Besides, the results also supported the findings by To et al. (2013), who found out that texts with high lexical density can be easier to read. Next, the research by Laufer and Nation (1995), who denoted that "good writings depicted more diverse vocabulary", also shared a resemblance with this study. That is, the researchers figured out that the more an author used different words in a text, with a small number of repetitions, the higher the lexical diversity (Juanggo, 2018). Regarding lexical sophistication, the results presented an effective use of academic word list (AWL) and off-list in research articles. It is worth noting that these two lists are categorized in lowfrequency words and are believed to be an indicator of the richness of academic writings (Laufer \& Nation, 1995). Furthermore, as AWL and off-list are considered as "rare words", the findings showing that ESL and EFL employed a large number of these types of words (2,577 and 2,436 tokens) implied that they carried a high level of language proficiency (Ha, 2019). Generally, lexical sophistication is often related to the level of difficulty in texts. Sari (2019) suggested that the texts could be regarded as difficult if the proportion of AWL surpassed 9\% of the whole texts. Consequently, based on the results, the research articles in this study, with $11.72 \%$ and $11.73 \%$ of AWL, were considered as difficult articles containing a richness of vocabulary and high-quality writing productions.

\section{CONCLUSION}

In conclusion, the findings revealed no significant difference in terms of lexical richness in the 40 research articles produced by ESL and EFL writers in all three distinct measures. In the light of the results, the researchers concluded that lexical richness in research articles between these two groups is fairly comparable. Furthermore, it is expected that this study provides a comprehensive view of lexical richness in scientific articles for readers to gain a better understanding and apply it in their future works. Besides, this study is also valuable for researchers, especially the novice, in utilizing some online tools such as LFP to initially analyze and develop their drafts regarding lexical richness. By doing so, the researchers will be aware of avoiding the tendency of "repetitive use of some levels of vocabulary" (Ibrahim et al., 2019) in producing quality research papers. In addition, ESL and EFL teachers, lecturers, and instructors are encouraged to use these online lexical analyzers to detect students who are struggling with writings due to poor productive vocabulary. The researchers believed that these tools can be used to lessen the burden in assisting students to hone their writing skills.

Notwithstanding, it is worth noting that this study has some limitations. First, the researchers only selected four countries, namely the Philippines, Malaysia, Indonesia, and Thailand, out of ten countries in the ASEAN to be representatives for ESL and EFL countries. Selecting more countries with more research articles would make the results stronger or selecting other countries instead of those four countries 
could give different findings that add more information to lexical studies. Second, the researchers merely selected research articles from educational fields. Therefore, it is believed that analyzing research articles from various branches among the writers of the ASEAN community would yield more profound and in-depth findings which will be greatly valuable for future studies. Lastly, as this study merely observed lexical richness among L2 authors in Southeast Asia, future researchers are encouraged to further conduct a study comparing lexical richness with nativespeaking countries. The researchers believed that the results from such studies could provide deeper and meaningful evidence of how lexical items are used in scientific journal articles.

\section{REFERENCES}

Apuke, O. D. (2017). Quantitative research methods: A synopsis approach. Kuwait Chapter of Arabian Journal of Business and Management Review, 33(5471), 18.

Astridya, F. W. (2020). Lexical richness of the expository writing in Indonesian by senior high school students. Celt: A Journal of Culture, English Language Teaching \& Literature, 20(1).

Azodi, N., Karimi, F., \& Vaezi, R. (2014). Measuring the Lexical Richness of Productive Vocabulary in Iranian EFL University Students' Writing Performance. Theory and Practice in Language Studies, 4(9), 1837-1849. https://doi.org/10.4304/tpls.4.9.1837-1849

Bestgen, Y. (2017). Beyond single-word measures: L2 writing assessment, lexical richness and formulaic competence. System, 69, 65-78. https://doi.org/doi.org/10.1016/j.system.2017.08.004

Covington, M. A., \& McFall, J. D. (2010). Cutting the gordian knot: The MovingAverage Type-Token Ratio (MATTR). Journal of Quantitative Linguistics, 17(2), 94-100.

Coxhead, A. (2000). A new academic word list. TESOL Quarterly, 34(2), 213-238.

Deerajviset, P. (2015). The ASEAN Community 2015 and English Language Teaching in Thailand. Journal of Humanities and Social Sciences, 39-73undefined.

Djiwandono, P. I. (2016). Lexical richness in academic papers: a comparison between students' and lecturers' essays. Indonesian Journal of Applied Linguistics, 5(2). https://doi.org/10.17509/ijal.v5i2.1345

Dumanig, F. P., \& Symaco, L. P. (2012). Competing roles of the national language and English in Malaysia and the Philippines: Planning, policy and use. Journal of International and Comparative Education (JICE), 104-115.

Engber, C. A. (1995). The relationship of lexical proficiency to the quality of ESL compositions. Journal of Second Language Writing, 4(2). https://doi.org/10.1016/1060-3743(95)90004-7

Indonesian Journal of EFL and Linguistics, 6(1), 2021 
Failasofah, F. (2018). Measuring Indonesian students' lexical diversity and lexical sophistication. Indonesian Research Journal in Education, 2(2), 97-107.

Fauzan, U., Lubis, A.H., \& Kurniawan, E. (2020). Rhetorical moves and linguistic complexity of research article abstracts in International Applied Linguistics Journals for English reading materials development. Asian ESP Journal, 16(5). Retrieved from https://www.asian-esp-journal.com/volume-16-issue-5-2october-2020/

González-López, S., \& López-López, A. (2015). Lexical analysis of student research drafts in computing. Computer Applications in Engineering Education, 23(4). https://doi.org/10.1002/cae.21638

Ha, H. S. (2019). Lexical Richness in EFL Undergraduate Students' Academic Writing. ENGLISH TEACHING, https://doi.org/10.15858/engtea.74.3.201909.3

Hoover, D. L. (2003). Another perspective on vocabulary richness. . Computers and Humanities, 37, 151-178.

Ibrahim, E. H. E., Muhamad, A. J., \& Esa, Z. (2019). A Comparison of Lexical Richness in L2 Written Productions. International Journal of Emerging Technologies in Learning (IJET), https://doi.org/10.3991/ijet.v14i20.11467

Indarti, D. (2019). Investigating lexical diversity of online English newspaper editorials across countries. . . Journal of Advanced English Studies, 2(2), 84101.

Indarti, Dwi. (2020). Lexical richness of newspaper editorials published in Southeast Asian countries. Studies in English Language and Education, 7(1). https://doi.org/10.24815/siele.v7i1.15032

Johansson, V. (2009). Lexical diversity and lexical density in speech and writing: a developmental perspective. Lund Working Papers in Linguistics, 52, 61-79.

Juanggo, W. (2018). Investigating lexical diversity and lexical sophistication of productive vocabulary in the written discourse of Indonesian EFL learners. Indonesian Journal of Applied Linguistics, 8(1). https://doi.org/10.17509/ijal.v8i1.11462

Kachru, B. (1985). Standards, codification and sociolinguistic realism: The English language in the outer circle. English in the World: Teaching and Learning the Language and Literature, 11-30.

Kirkpatrick, A. (2010). English as a lingua franca in ASEAN: A multilingual model (Vol. 1). Hong Kong: Hong Kong University Press.

Laufer, B., \& Nation, P. (1995). Vocabulary Size and Use: Lexical Richness in L2 Written Production. Applied Linguistics, 16(3). https://doi.org/10.1093/applin/16.3.307

Lei, S., \& Yang, R. (2020). Lexical richness in research articles: Corpus-based comparative study among advanced Chinese learners of English, English native beginner students and experts. . . Journal of English for Academic Purposes, 47. 
Martin, I. P. (2014). English language teaching in the Philippines. World Englishes, $33(4), 472-485$.

Noom-Ura, S. (2013). English-teaching problems in Thailand and Thai teachers' professional development needs. English Language Teaching, 6(11), 139-147.

Read, J. (2000). Assessing Vocabulary. . Cambridge: Cambridge University Press.

Rochma, A. F., \& Triyono, S. (2019). A discourse analysis: Cohesion of the introduction section of research article. Journal of English Language Teaching and Linguistics, 4(1). Retrieved from https://jeltl.org/index.php/jeltl/article/view/173

Sari, W. A. (2019). Lexical richness and syntactic complexity of the English exam papers of SBMPTN . Universitas Airlangga, Surabaya.

Schmitt, N. (2000). Vocabulary in language teaching. Cambridge: Cambridge University Press.

Šišková, Z. (2012). Lexical richness in EFL students' narratives. University of Reading Language Studies Working Papers, 4, 26-36.

To, V., Fan, S., \& Thomas, D. (2013). Lexical density and readability: A case study of English textbooks. Internet Journal of Language, Culture and Society, 37, $61-71$.

Ulla, M. B. (2018). English language teaching in Thailand: Filipino teachers' experiences and perspectives. Issues in Educational Research, 28(4), 1080undefined.

Ure, J. (1971). Lexical density and register differentiation. In G. Perren and J.L.M. Trim (Ed.), . In G. Perren and J.L.M. Trim (eds), Applications of Linguistics, London: Cambridge University Press. 443-452. (p. .443-452). London: Cambridge University Press.

West, M. (1953). A general service list of English words. London: Longman. 